\title{
Copper-Containing Amine Oxidases and FAD-Dependent Polyamine Oxidases Are Key Players in Plant Tissue Differentiation and Organ Development
}

\author{
Paraskevi Tavladoraki, Alessandra Cona and Riccardo Angelini * \\ Laboratory of Biochemistry, Physiology and Biotechnology of Plants, Department of Science, University "Roma Tre", Rome, \\ Italy
}

Plant polyamines are catabolized by two classes of amine oxidases, the copper amine oxidases (CuAOs) and the flavin adenine dinucleotide (FAD)-dependent polyamine oxidases (PAOs). These enzymes differ to each other in substrate specificity, catalytic

OPEN ACCESS

Edited by:

Juan Francisco Jimenez Bremont, Instituto Potosino de Investigacion

Cientifica y Tecnologica, Mexico

Reviewed by:

Andres Garriz,

Instituto de Investigaciones Biotecnológicas Instituto Tecnológico

Chascomús, Argentina Anna Kärkönen,

University of Helsinki, Finland

*Correspondence:

Riccardo Angelin

riccardo.angelini@uniroma3.it

Specialty section:

This article was submitted to Plant Physiology,

a section of the journal Frontiers in Plant Science

Received: 22 March 2016 Accepted: 26 May 2016

Published: 28 June 2016

Citation:

Tavladoraki P, Cona A and Angelini R (2016) Copper-Containing Amine

Oxidases and FAD-Dependent Polyamine Oxidases Are Key Players in Plant Tissue Differentiation and Organ Development.

Front. Plant Sci. 7:824. doi: 10.3389/fp/s.2016.00824 mechanism and subcellular localization. CuAOs and PAOs contribute to several physiological processes both through the control of polyamine homeostasis and as sources of biologically-active reaction products. CuAOs and PAOs have been found at high level in the cell-wall of several species belonging to Fabaceae and Poaceae families, respectively, especially in tissues fated to undertake extensive wall loosening/stiffening events and/or in cells undergoing programmed cell death (PCD). Apoplastic CuAOs and PAOs have been shown to play a key role as a source of $\mathrm{H}_{2} \mathrm{O}_{2}$ in light- or developmentally-regulated differentiation events, thus influencing cell-wall architecture and maturation as well as PCD. Moreover, growing evidence suggests a key role of intracellular CuAOs and PAOs in several facets of plant development. Here, we discuss recent advances in understanding the contribution of different CuAOs/PAOs, as well as their cross-talk with different intracellular and apoplastic metabolic pathways, in tissue differentiation and organ development.

Keywords: polyamines, copper amine oxidases, FAD-dependent polyamine oxidases, cell-wall, tissue differentiation, reactive oxygen species, growth regulation, programmed cell death

\section{COPPER-CONTAINING AMINE OXIDASES AND FAD-DEPENDENT POLYAMINE OXIDASES: A COMPLEX NETWORK}

In plants, the polyamines (PAs) putrescine (Put), cadaverine (Cad), spermidine (Spd), spermine $(\mathrm{Spm})$, and thermospermine (Therm-Spm) are involved in several physiological processes, such as cell proliferation, differentiation and defense responses (Takahashi and Kakehi, 2010; Marina et al., 2013; Jiménez-Bremont et al., 2014; Tiburcio et al., 2014; Pál et al., 2015; Strohm et al., 2015; Yoshimoto et al., 2016). PAs are oxidized by a heterogeneous class of enzymes which includes copper-containing amine oxidases (CuAOs) and FAD-dependent polyamine oxidases (PAOs) (Cona et al., 2006a; Angelini et al., 2010; Tavladoraki et al., 2012). CuAOs oxidize mainly Put and Cad, and less efficiently Spd and Spm at the primary amino groups, producing ammonia, 
$\mathrm{H}_{2} \mathrm{O}_{2}$ and an aminoaldehyde and are thus considered involved in PA terminal catabolism. In Arabidopsis thaliana $10 \mathrm{CuAO}$ genes are present, among which only eight encode for

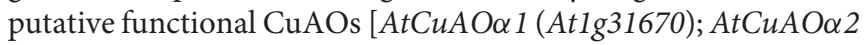

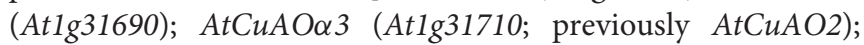
AtCuAO $\beta$ (At4g14940; prev. ATAO1 or AtAO1); AtCuAOr 1

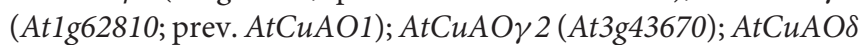

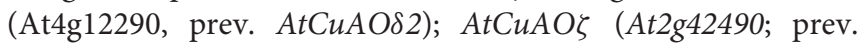
AtCuAO3 or AtCuAO1)] ${ }^{1}$ (Figure 1). The remaining two genes $A t C u A O \varepsilon 1$ (At4g12270; prev. AtCuAOE) and $A t C u A O \varepsilon 2$ (At4g12280; prev. AtCuAOS1) are consecutive fragments of a copy of $A t C u A O \delta$ gene. Phylogenetic analysis evidenced that plant $\mathrm{CuAOs}$ form three clades (I-III), clade I being composed of three subgroups (Ia-Ic) and clade II of two (IIa and IIb; Figure 1A). Furthermore, genomic sequence analysis demonstrated that the Arabidopsis CuAOs of clades I and II, but not of clade III, present a similar gene structure to each other with three introns at conserved positions (Figure 1B). This suggests that $A t C u A O \alpha 1$ to $A t C u A O \delta$ are recent derivatives of a common ancestor.

AtCuAO $\beta$ (clade Ic), AtCuAO $\gamma 1$ (clade IIa) as well as Pisum sativum, Lens culinaris and Euphorbia characias CuAOs (PSAO, LSAO, and ELAO, respectively; clade Ia) are localized in the apoplast (Rossi et al., 1992; Tipping and McPherson, 1995; Møller and McPherson, 1998; Padiglia et al., 2002; Boudart et al., 2005; Planas-Portell et al., 2013), whereas AtCuAO $\zeta$, Malus domestica CuAO1 (MdAO1) and the other members of clade III in peroxisomes (Planas-Portell et al., 2013; Naconsie et al., 2014; Qu et al., 2014; Zarei et al., 2015a; Table 1). Peroxisomal localization was also shown for AtCuAO 3 (Planas-Portell et al., 2013) despite the apparent lack of canonical signal for peroxisomal localization and the fact that it is clustered together with the extracellular PSAO and LSAO. For MdAO2, which is clustered together with AtCuAO $\delta$ in clade IIb, both intracellular and apoplastic localization was shown (Zarei et al., 2015a).

Although, most of the so far characterized CuAOs, such as AtCuAO $\beta$, AtCuAO $\gamma 1, A t C u A O \alpha 3, A t C u A O \zeta$, PSAO, LSAO, and Nicotiana tabacum CuAO1 (NtDAO1), oxidize mainly Put, Cad, and Spd (Rossi et al., 1992; Tipping and McPherson, 1995; Møller and McPherson, 1998; Planas-Portell et al., 2013; Naconsie et al., 2014), MdAO1 of clade III shows preference for 1,3-diaminopropane (Dap), having no activity with Spd (Zarei et al., 2015a). Furthermore, AtCuAO $\zeta$ and NtDAO1 oxidize also $N$-methyl-Put, though less efficiently than the nonmethylated diamine. Thus, they differ from the N. tabacum $N$ methylputrescine oxidase (Nt-MPO1), which shows preference for $N$-methyl-Put and is involved in nicotine biosynthesis, although all three proteins are clustered together in clade III (Heim et al., 2007; Katoh et al., 2007; Dewey and Xie, 2013; Naconsie et al., 2014). This indicates that clade III consists of a heterogeneous group of CuAOs. Another remarkable finding is the higher catalytic activity of $\mathrm{MdAO} 2$ with monoamines, such as 2-phenylethylamine, tyramine and tryptamine, than

\footnotetext{
${ }^{1}$ Due to heterogeneity of $C u A O$ gene classification in literature, we have renumbered them according to $\mathrm{Qu}$ et al. (2014) with some modifications taking into consideration the phylogenetic analysis (Figure 1). We trust that this will help for future use.
}

with Put and Spd (Zarei et al., 2015a). Interestingly, tyramine is also a substrate of ELAO whereas tryptamine and other indoleamines are both substrates and inhibitors of LSAO (Medda et al., 1997; Pintus et al., 2013). It was speculated that 2phenylacetaldehyde produced by $\mathrm{MdAO} 2$-mediated oxidation of 2-phenylethylamine may be converted in fruits to 2phenylethanol, a volatile compound that is a major contributor to fruit flavor and flower fragrance. It is also possible that 4hydroxyphenylacetaldehyde produced by tyramine oxidation is involved in benzylisoquinoline alkaloid biosynthesis in plants (Zarei et al., 2015a).

PAOs oxidize the secondary amino groups of a series of PAs and reaction products depend on the catalytic mechanism and substrate specificity. The apoplastic PAOs oxidize the carbon at the endo-side of the $\mathrm{N}^{4}$ atom of Spd and Spm producing Dap, $\mathrm{H}_{2} \mathrm{O}_{2}$, and an aminoaldehyde (Tavladoraki et al., 1998; Cervelli et al., 2001; Liu et al., 2014b), whereas all the intracellular PAOs oxidize the carbon at the exo-side of the $\mathrm{N}^{4}$ atom of Spd or Spm, to produce Put or Spd, respectively, together with $\mathrm{H}_{2} \mathrm{O}_{2}$ and 3-aminopropanal (Tavladoraki et al., 2006; Kamada-Nobusada et al., 2008; Moschou et al., 2008b; Fincato et al., 2011; Ahou et al., 2014; Kim et al., 2014; Liu et al., 2014a; Mo et al., 2015). Some of the intracellular PAOs are also able to oxidize ThermSpm and norspermine (Nor-Spm) with the production of Spd and norspermidine (Nor-Spd), respectively (Tavladoraki et al., 2006; Fincato et al., 2011; Kim et al., 2014; Liu et al., 2014a). Recently, a Selaginella lepidophylla PAO (SelPAO5) was shown to produce Nor-Spd from Therm-Spm (Sagor et al., 2015). These differences in reaction products reflect differences in position and orientation of the substrate inside the catalytic site. Both the exo- and endo-mode of PA oxidation produce a biologically active diamine or triamine which can be converted to higher PAs. Indeed, even Dap, which has a role in the control of stomata movement through its acetylated form (Jammes et al., 2014), can be converted by aminopropyltransferases to Nor-Spd and subsequently to Nor-Spm, two PAs correlated to stress tolerance (Kuehn et al., 1990; Fuell et al., 2010; Sagor et al., 2015). In this way, all PAOs can be considered involved in PA back-conversion. This view changes the prevailing idea that the PAOs with an endo-mode of substrate cleavage are involved in PA terminal catabolism, thus attributing to $\mathrm{CuAOs}$ the role of PA terminal catabolism which permits nitrogen and carbon re-assimilation to various biochemical reactions (Moschou et al., 2012).

In Arabidopsis five PAOs are present (AtPAO1-AtPAO5), which are localized intracellularly and show an exo-mode of substrate oxidation. AtPAO1 and AtPAO5 present cytosolic localization and a preference for Spm, Therm-Spm, and NorSpm, as substrates (Tavladoraki et al., 2006; Ahou et al., 2014; Kim et al., 2014; Liu et al., 2014a). AtPAO5 accepts also $N^{1}$ acetyl-Spm as a substrate and appears to be a peculiar PAO, having a better activity as a dehydrogenase rather than as an oxidase (Ahou et al., 2014). AtPAO2, AtPAO3, and AtPAO4 are localized in the peroxisomes and oxidize both Spd and Spm (Kamada-Nobusada et al., 2008; Moschou et al., 2008b; Takahashi et al., 2010; Fincato et al., 2011; Sequera-Mutiozabal et al., 2016). Furthermore, AtPAO2, AtPAO3, and AtPAO4 present similar gene structures and tissue-specific expression patterns (root tips, 


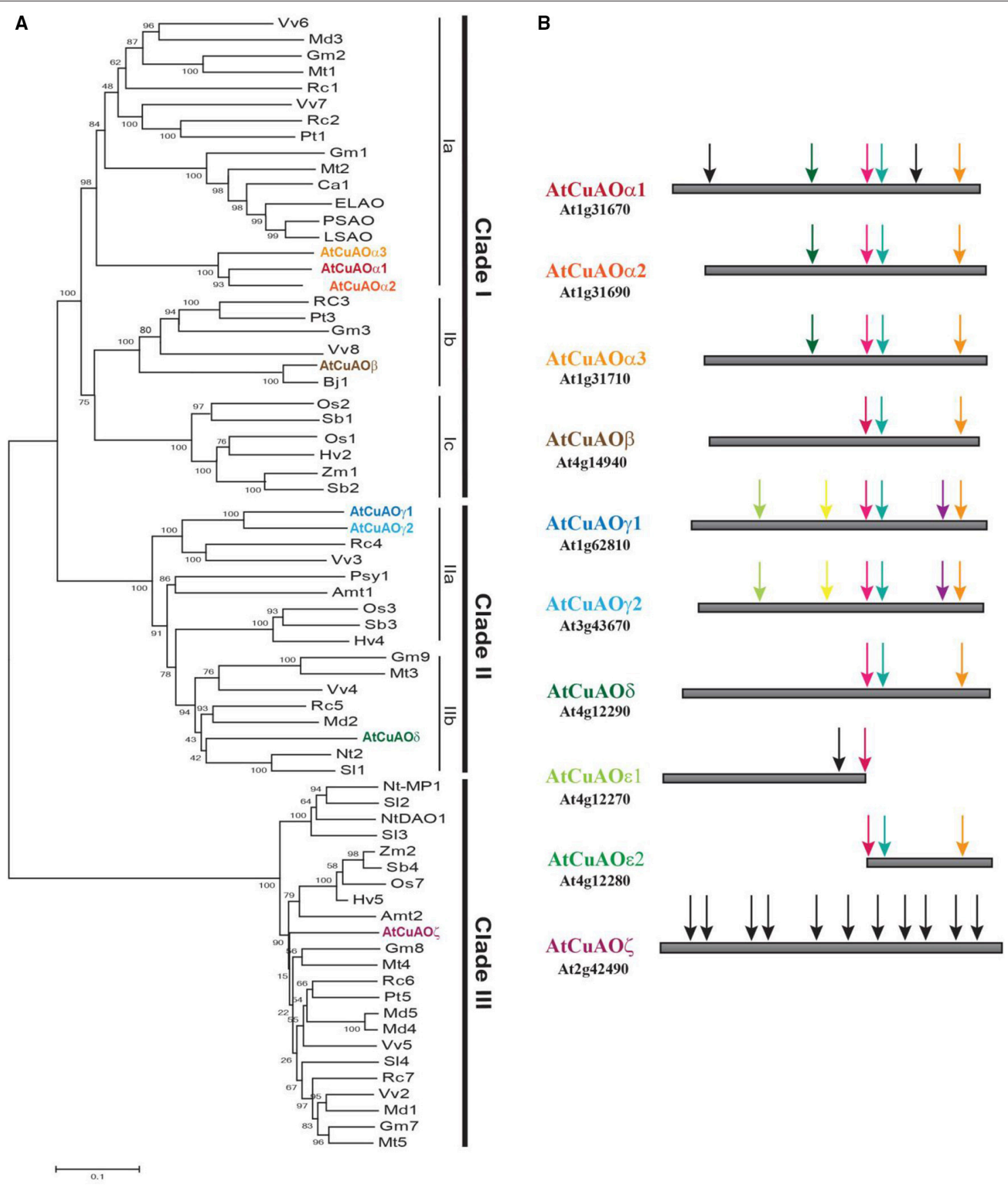

FIGURE 1 | Sequence analysis of plant CuAOs. (A) Phylogenetic analysis of CuAOs from selected spermatophytes. Plant CuAOs form three principal supported clades (I-III). Clade I consists of three groups (groups a and b consisting of CuAOs from dicots and group c from monocots), the reciprocal relationship of which is not well resolved. For simplicity reasons, for each distinct group only a representative CuAO from each plant species was considered. Amino acid sequences were aligned with ClustalW (McWilliam et al., 2013) and phylogenetic analysis was performed using MEGA5 (Tamura et al., 2011) software with the neighbor-joining algorithm. Bootstrap values obtained with 1000 replicates are indicated at the nodes. Accession number of proteins are indicated in Supplementary Table S1. (B) Genomic sequence analysis of Arabidopsis CuAOs (AtCuAOs). Black arrows show not conserved intron positions, while arrows of the same color indicate conserved intron positions. All AtCuAOs of clades I and II have three introns at conserved positions which suggests a recent common ancestor. However, based on the presence of additional introns, some of them placed at positions conserved among the members of the same group, but not among those of different groups, an independent

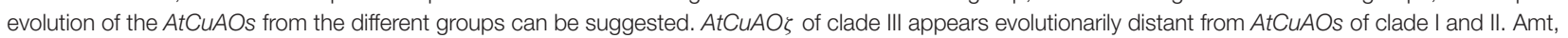
Amborella trichopoda; Bj, Brassica juncea; Ca, Cicer arietinum; ELAO, CuAO from latex of Euphorbia characias; Gm, Glycine max; Hv, Hordeum vulgare; LSAO, CuAO from seedlings of Lens culinaris; Md, Malus domestica; Mt, Medicago truncatula; Nt, Nicotiana tabacum; Os, Oryza sativa; PSAO, CuAO from seedlings of Pisum sativum; Psy, Pinus sylvestris; Pt, Populus trichocarpa; Rc, Ricinus communis; Sb, Sorghum bicolor; Sl, Solanum lycopersicum; Vv, Vitis vinifera; Zm, Zea mays. 


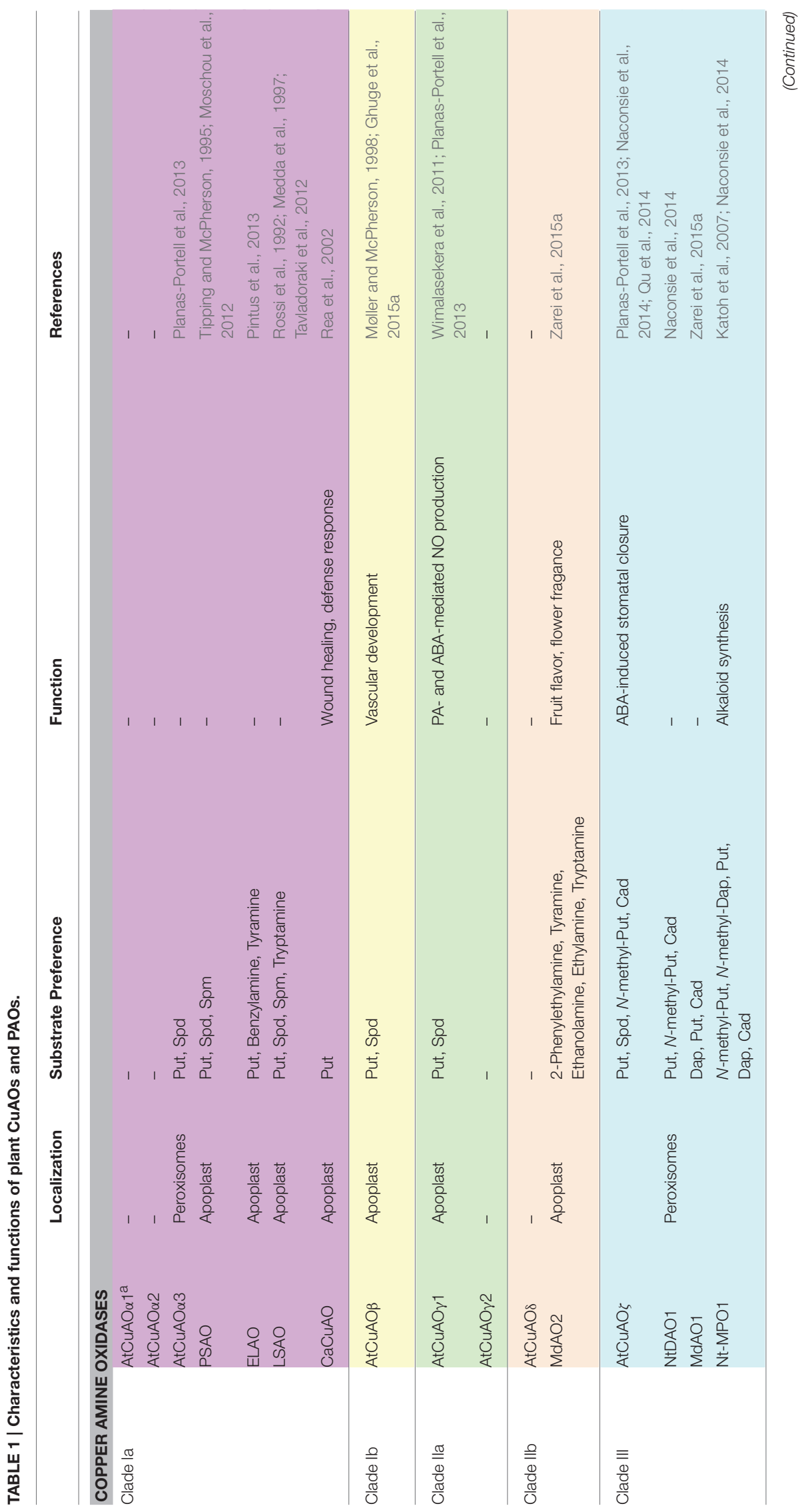




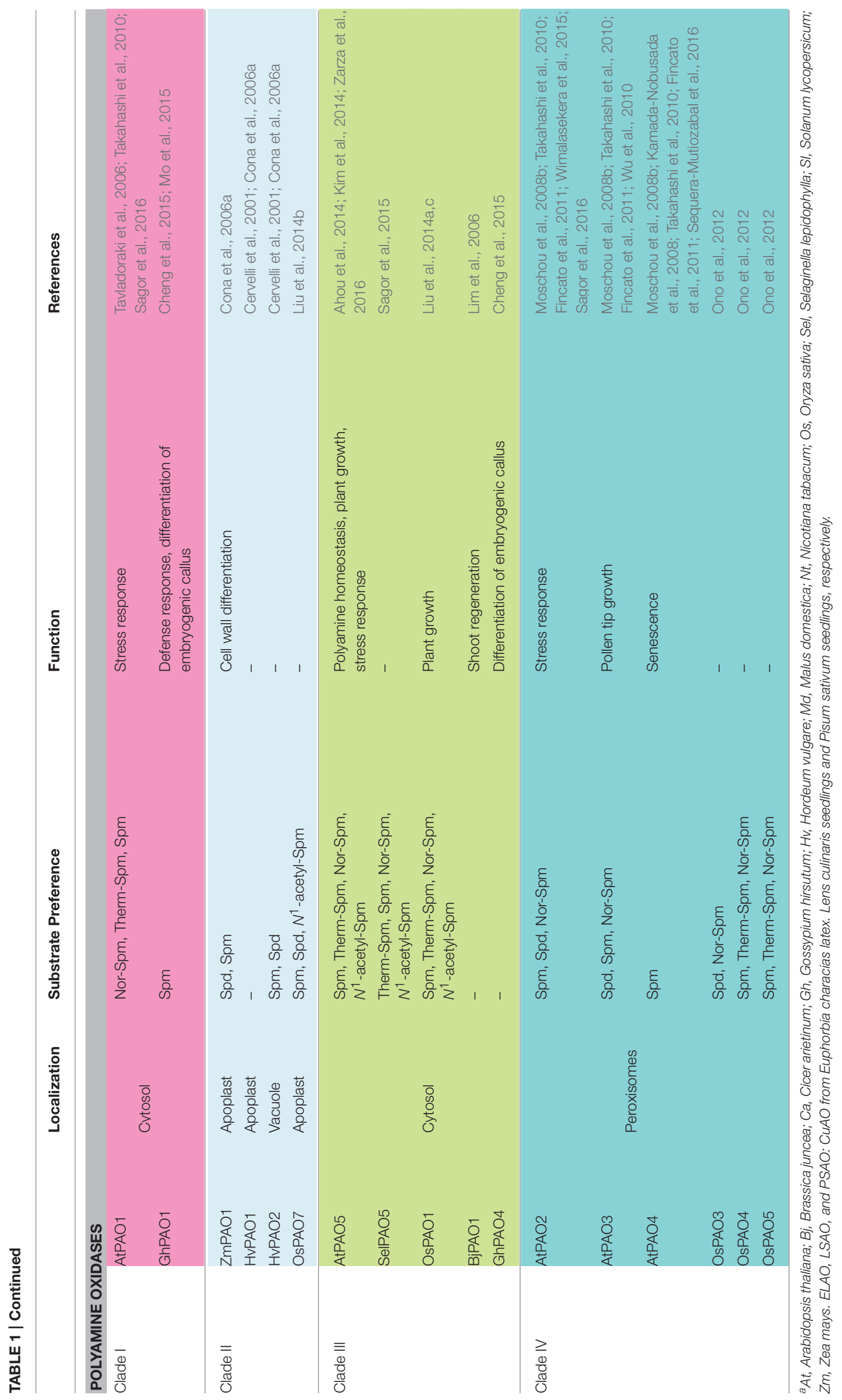


guard cells and pollen grains; Takahashi et al., 2010; Fincato et al., 2012). Phylogenetic studies showed that PAOs are divided into four major clades (Liu et al., 2014a; Wang and Liu, 2015). Worth noticing is the fact that the PAOs of the same clade present some common characteristics (Table 1). In particular, clade I PAOs have cytosolic localization and oxidize specifically Spm but not Spd, while clade IV PAOs present peroxisomal localization and specificity for either Spm or Spd or both. The apoplastic PAOs of clade II show preference for both Spm and Spd and are characterized by a $k_{\text {cat }}$ value at least 10 -fold higher than that of the PAOs of the other clades. Clade III PAOs are cytosolic enzymes which recognize Spm, Therm-Spm, Nor-Spm, and $N^{1}$-acetyl Spm as substrates and are regulated by PAs (Ahou et al., 2014; Kim et al., 2014; Liu et al., 2014a; Wang and Liu, 2015). Furthermore, they present very low $k_{\text {cat }}$ values as oxidases, which indicate that not only AtPAO5 but all AtPAO5 orthologs may have activity mainly as dehydrogenases (Ahou et al., 2014).

\section{CELL-WALL AMINE OXIDASES: DRIVING ROS PRODUCTION IN THE APOPLASTIC "HUB"}

Compelling evidence supports a key role for reactive oxygen species (ROS; superoxide anion, $\mathrm{O}_{2}^{\bullet-} ; \mathrm{H}_{2} \mathrm{O}_{2}$; hydroxyl radical, - $\mathrm{OH}$; singlet oxygen, ${ }^{1} \mathrm{O}_{2}$ ) and nitric oxide (NO) in orchestrating developmental processes, as well as in being involved in signaling of both local and systemic defense responses in plants. The apoplast is a major "hub" for these chemical species. Their accumulation in large amounts and the complexity of the regulatory mechanisms involved in their biosynthesis reflect the peculiar role of this compartment in physiological events that depend on temporarily regulated and spatially restricted ROS and NO signatures (Kärkönen and Kuchitsu, 2015). Indeed, ROS are key players in cell-wall loosening and stiffening, as well as in developmental cell death, and stress-related events, such as the two-phase oxidative burst, wound-healing and the hypersensitive response (De Pinto et al., 2012; Kärkönen and Kuchitsu, 2015). Furthermore, ROS generated in the apoplast may well influence $\mathrm{Ca}^{2+}$ transport across plasma membrane thus inducing a multiplicity of $\mathrm{Ca}^{2+}$-mediated responses (Gilroy et al., 2014; Pottosin et al., 2014). Systems involved in ROS biosynthesis in the apoplast include plasma membrane NADPH oxidases and quinone reductases, cell-wall peroxidases (PODs), oxalate oxidases, amine oxidases (Kärkönen and Kuchitsu, 2015). Non enzymatic ${ }^{\bullet} \mathrm{OH}$ production can be also driven by Fenton-type reaction dependent on a reducing agent (for example ascorbate), transition metal ions and $\mathrm{H}_{2} \mathrm{O}_{2}$ (Schopfer et al., 2002; Müller et al., 2009). Although, a very significative amount of data suggests NADPH oxidases and/or PODs to have a prevalent role in ROS production in response to microbial pathogens, wounding, as well as in development-related events, the contribution of other systems has been largely underestimated (Cona et al., 2006a,b; Monshausen et al., 2007; Angelini et al., 2008; Kärkönen and Kuchitsu, 2015; Roach et al., 2015). This consideration derives mainly from the analysis of literature data based on extensive use of diphenyleneiodonium (DPI), sodium azide or potassium cyanide and diethyldithiocarbamate (DDC) as diagnostic tools for the involvement of $\mathrm{NADPH}$ oxidase, POD or superoxide dismutase activity, respectively, in ROS production. However, these compounds are inhibitors of CuAOs (DDC, azide, cyanide) and PAOs (DPI) as well (Cona et al., 2006b; Medda et al., 2009). Noteworthy, a cross-talk has been recently suggested between AtPAO3 and NADPH oxidase activity, affecting ROS homeostasis and respiration rate in Arabidopsis (Andronis et al., 2014). On the other hand, several evidences support a role of PAs not only in ROS production, but also in that of NO (Tun et al., 2006; Pál et al., 2015). Indeed, loss-of-function atcuao 1 and atpao 2 mutants are impaired in PA- and/or abscisic acid (ABA)-mediated NO production (Wimalasekera et al., 2011, 2015).

\section{POLYAMINE OXIDATION IN THE APOPLAST: CELL-WALL MODIFICATIONS AND GROWTH REGULATION}

Early studies in legumes, as well as in maize and tobacco plants evidenced a close correlation between tissue distribution of cellwall associated $\mathrm{CuAO}, \mathrm{PAO}$, and POD activities (Federico and Angelini, 1991; Rea et al., 2002; Paschalidis and RoubelakisAngelakis, 2005). These studies, also supported by the use of mechanism-based specific inhibitors, suggested a role of PA oxidation in providing $\mathrm{H}_{2} \mathrm{O}_{2}$ for POD activity during cell-wall cross-linking, lignification and/or suberization processes taking place in the course of organ development, de-etiolation, or wound-healing (Cona et al., 2003, 2006a, 2014; Angelini et al., 2008). A role for lignin synthesis in anther cell-walls has been also hypothesized for an Oryza sativa PAO (OsPAO7; Liu et al., 2014b). The major concern raised by these studies comes from the low levels or even absence of PAs in the apoplast under physiological growth conditions (Rea et al., 2004). However, this issue was overcome by the observation that PAs are secreted in the apoplastic milieu during specific developmental phases or under biotic and abiotic stress conditions (Yoda et al., 2003; Moschou et al., 2008a; Rodríguez et al., 2009). On the other hand, in Zea mays, PAO-mediated $\mathrm{H}_{2} \mathrm{O}_{2}$ production in the apoplast significantly contributes to leaf blade elongation, possibly through Fenton and/or Haber-Weiss type reactions driving ${ }^{\bullet} \mathrm{OH}$ synthesis (Rodríguez et al., 2009). A similar role has been suggested in Glycine max hypocotyls for the putative apoplastic GmCuAO1 (Delis et al., 2006). This contribution is particularly important under salt stress conditions which inhibit both NADPH oxidases and apoplastic POD activities and induce secretion of PAs in the apoplast (Rodríguez et al., 2009; Campestre et al., 2011; Shoresh et al., 2011).

\section{APOPLASTIC CuAOs AND PAOs: DEVELOPMENTAL PCD AND ROOT XYLEM DIFFERENTIATION}

It is well established that ROS have a key role in programmed cell death (PCD) in plants (De Pinto et al., 2012). Although, cell-wall maturation and lignification is intimately connected 
to the cell-death phase of xylem tissue differentiation, it is difficult to distinguish specific ROS contribution to each specific event (Bollhöner et al., 2012). Notably, transition between cell proliferation and tissue differentiation in the root is regulated independently by either hormonal balance (auxin and citokinin) or ROS $\left(\mathrm{O}_{2}^{\bullet-}\right.$ and $\mathrm{H}_{2} \mathrm{O}_{2}$ ) distribution (Tsukagoshi et al., 2010). Several lines of evidence links PA oxidation in the apoplast and concomitant ROS production with cellwall maturation and developmental PCD in particular during xylem tissue differentiation. Møller and McPherson (1998) demonstrated that AtCuAO $\beta$ expression in root xylem tissues precedes and overlaps with lignin synthesis in Arabidopsis. Furthermore, although the roots of loss-of-function atcuao $\beta$ mutants did not display evident changes as compared to wild-type plants during normal growth, methyl jasmonate induced early protoxylem differentiation in roots of wildtype plants, concomitantly with increased AtCuAO $\beta$ expression levels, decreased Put levels and $\mathrm{H}_{2} \mathrm{O}_{2}$ accumulation. As these events do not occur in atcuao $\beta$ roots, a role of $A t C u A O \beta$ in protoxylem differentiation under stress condition can be suggested (Ghuge et al., 2015a,c). On the other hand, tobacco plants over-expressing a fungal endopolygalacturonase, releasing cell-wall derived oligogalacturonides and mediating both developmental events and defense responses, showed higher $\mathrm{CuAO}$ activity, lower Put level, $\mathrm{H}_{2} \mathrm{O}_{2}$ accumulation and an earlier root xylem differentiation. These events were reverted by 2-bromoethylamine, a mechanism-based $\mathrm{CuAO}$ inhibitor (Cona et al., 2014). Furthermore, it has been observed that active $\mathrm{ZmPAO}$ and $\mathrm{H}_{2} \mathrm{O}_{2}$ accumulate in root xylem and xylem parenchyma tissues early during their differentiation (Tisi et al., 2011). N-prenylagmatine, a specific PAO inhibitor, inhibited secondary cell-wall deposition, while exogenous Spd induced DNA fragmentation and nuclei condensation, thus suggesting a role for PAO in providing $\mathrm{H}_{2} \mathrm{O}_{2}$ during secondary wall deposition and developmental PCD in xylem tissue (Tisi et al., 2011). Moreover, over-expression of ZmPAO1, as well as down-regulation of the gene encoding S-adenosyl-L-methionine decarboxylase via RNAi in tobacco plants promoted vascular cell differentiation and induced PCD in root cap cells suggesting that the balance between intracellular PA anabolism and apoplastic catabolism is an integrated signaling system coordinating PCD or stress tolerance (Moschou et al., 2008a; Tisi et al., 2011).

\section{PEROXISOMAL PAOS: INVOLVEMENT IN POLLEN TUBE AND ROOT GROWTH}

PAs and ROS deriving from their oxidation regulate ion channels both in animals and plants during different physiological and stress-response processes directly influencing plasma membrane ion transport and/or acting as second messengers (Pegg, 2014; Pottosin et al., 2014). In particular, $\mathrm{H}_{2} \mathrm{O}_{2}$ produced through Spd oxidation by the peroxisomal AtPAO3, which is highly expressed in pollen grains also during pollen tube growth (Fincato et al., 2012), was shown to trigger the opening of hyperpolarization activated $\mathrm{Ca}^{2+}$-permeable channels in pollen tubes, thus altering the tip-specific cytosolic $\mathrm{Ca}^{2+}$ gradient which plays a pivotal role in controlling pollen tube elongation $(\mathrm{Wu}$ et al., 2010). Indeed, two loss-of-function Arabidopsis atpao3 mutants presented reduced pollen tube growth rate and seed production. Peroxisomal OsPAO3, OsPAO4, and OsPAO5 (Ono et al., 2012) are coherently expressed in anthers (Liu et al., 2014b). More studies are necessary to determine in detail the effect of PAs on pollen maturation, since the effect seems to be complex involving PA conjugation, ROS formation/scavenging, and celldeath events (Aloisi et al., 2015). Furthermore, based on the vigorous root growth of AtPAO2 over-expressor plants and the hypersensitivity of atpao2 loss-of-function mutant plants to ABA, it has been recently hypothesized a positive function of AtPAO2 in Arabidopsis root growth (Wimalasekera et al., 2015).

\section{CuAOs AND PAOs IN STOMATA MOVEMENT AND FRUIT RIPENING}

ROS and calcium signatures in guard cells, as well as ion transport from the apoplast into the cytosol and from the cytosol for storage in the vacuole are important components of the regulatory network controlling stomata movements (Kollist et al., 2014; Murata et al., 2015). In Vicia faba, it has been shown that ABA-mediated stomata closure involves induction of an apoplastic $\mathrm{CuAO}$ activity as a source of $\mathrm{H}_{2} \mathrm{O}_{2}$, and that this activity is necessary to increase cytosolic $\mathrm{Ca}^{2+}$ levels in response to ABA (An et al., 2008). Consistently with these observations, the apoplastic AtCuAO $\beta$ was shown to be expressed in guard cells (Ghuge et al., 2015b). In addition, the peroxisomal AtCuAO $\zeta$ which is expressed in guard cells is also involved in the ABA-mediated control of stomata opening (Qu et al., 2014). PAOs were also shown to contribute to the control of stomata movement in Vitis vinifera and Arabidopsis (Paschalidis et al., 2010; Hou et al., 2013).

PA catabolism has been also associated with grape and tomato fruit ripening (Agudelo-Romero et al., 2013; Tsaniklidis et al., 2016). Despite the increase of arginine decarboxylase expression levels during grape fruit ripening, the level of free and conjugated PAs was strongly decreased. This decrease was accompanied by up-regulation of two $\mathrm{CuAOs}$ and three $P A O$ genes, one CUAO and two PAOs of them encoding for proteins with putative peroxisomal localization (AgudeloRomero et al., 2013). Increase of $\mathrm{CuAO}$ and PAO activity, as well of $\mathrm{H}_{2} \mathrm{O}_{2}$ production during fruit maturation, was also observed. Furthermore, the relatively high expression levels of Solanum lycopersicum $\mathrm{CuAO}$ (SlCuAO1), which is clustered together with AtCuAO $\delta$ in clade IIb, was attributed to the implication of PA metabolism in physiological processes taking place during fruit ripening (Tsaniklidis et al., 2016). The up-regulation of $\mathrm{CuAOs/PAOs} \mathrm{during} \mathrm{ripening} \mathrm{may} \mathrm{constitute} \mathrm{a} \mathrm{source} \mathrm{of} \mathrm{ROS}$ for signaling events leading to the acceleration of the ripening process. It is also possible that PA catabolism interferes with plant hormonal pathways, such as ethylene and ABA (AgudeloRomero et al., 2013). Alternatively, 4-aminobutanal produced through PA catabolism can be metabolized to $\gamma$-aminobutyric acid by an aminoaldehyde dehydrogenase (Zarei et al., 2015b) and enter into the Krebs cycle, thus constituting a link between nitrogen and carbon metabolism (Moschou et al., 2012). 


\section{CYTOSOLIC PAOS IN THE CONTROL OF THERM-SPM LEVELS}

Loss-of-function Arabidopsis mutants for AtPAO5 present increased levels of Therm-Spm, $N^{1}$-acetyl-Spm and Spm which are the substrates of the enzyme (Ahou et al., 2014; Kim et al., 2014; Sagor et al., 2016; Zarza et al., 2016). Interestingly, the expression levels of AtPAO5, as well as of its functional orthologue in rice (OSPAO1), are controlled by Therm-Spm and Spm (Ahou et al., 2014; Liu et al., 2014a,c). This indicates the necessity for a fine tune regulation of PA levels for proper growth and stress response, since levels above an upper limit or below a threshold may be detrimental for the plants. Indeed, the atpao5 mutants present altered growth parameters at late developmental stages mainly due to the increased Therm-Spm levels (Kim et al., 2014), as have been also observed in mutants for Therm-Spm synthase and S-adenosylmethionine decarboxylase with reduced Therm-Spm levels (Clay and Nelson, 2005; Ge et al., 2006; Yoshimoto et al., 2016). Furthermore, the atpao5 mutants were hypersensitive to low doses of exogenous Therm-Spm (Kim et al., 2014; Liu et al., 2014c).

\section{INTRACELLULAR PAOs AND SOMATIC EMBRYOGENESIS}

Some studies suggest that in Gossypium hirsutum an AtPAO1like (GhPAO1) and an AtPAO5-like (GhPAO4) PAO may play a crucial role in the generation and differentiation of embryogenic callus during somatic embryogenesis (Cheng et al., 2015). Indeed, PAO activity levels significantly increased during conversion of embryogenic callus into somatic embryos, and inhibition of PAO activity by 1,8 -diaminooctane resulted in brown and necrotic cultures, and a significant decrease in both fresh weight and somatic embryo number. Importantly, the negative effects of 1,8 diaminooctane were reversed by application of exogenous $\mathrm{H}_{2} \mathrm{O}_{2}$.

\section{REFERENCES}

Agudelo-Romero, P., Bortolloti, C., Pais, M. S., Tiburcio, A. F., and Fortes, A. M. (2013). Study of polyamines during grape ripening indicate an important role of polyamine catabolism. Plant Physiol. Biochem. 67, 105-119. doi: 10.1016/j.plaphy.2013.02.024

Ahou, A., Martignago, D., Alabdallah, O., Tavazza, R., Stano, P., Macone, A., et al. (2014). A plant spermine oxidase/dehydrogenase regulated by the proteasome and polyamines. J. Exp. Bot. 65, 1585-1603. doi: 10.1093/jxb/eru016

Aloisi, I., Cai, G., Tumiatti, V., Minarini, A., and Del Duca, S. (2015). Natural polyamines and synthetic analogs modify the growth and the morphology of Pyrus communis pollen tubes affecting ROS levels and causing cell death. Plant Sci. 239, 92-105. doi: 10.1016/j.plantsci.2015.07.008

An, Z., Jing, W., Liu, Y., and Zhang, W. (2008). Hydrogen peroxide generated by copper amine oxidase is involved in abscisic acid-induced stomatal closure in Vicia faba. J. Exp. Bot. 59, 815-825. doi: 10.1093/jxb/ erm 370

Andronis, E. A., Moschou, P. N., Toumi, I., and Roubelakis-Angelakis, K. A. (2014). Peroxisomal polyamine oxidase and NADPH-oxidase cross-talk for ROS homeostasis which affects respiration rate in Arabidopsis thaliana. Front. Plant Sci. 5:132. doi: 10.3389/fpls.2014.00132
Furthermore, in Arabidopsis, AtPAO5 and its B. juncea ortholog $(B j P A O)$ have a role in shoot regeneration from root cultures (Lim et al., 2006).

\section{CONCLUDING REMARKS}

Numerous recent studies have evidenced an extraordinary complexity in $\mathrm{CuAO}$ and $P A O$ gene families regarding catalytic activity, subcellular localization, expression pattern and physiological roles of the encoded proteins. Indeed, important links to developmental and stress-related events are emerging for $\mathrm{CuAOs}$ and PAOs through ROS/NO production and regulation of specific PA levels.

\section{AUTHOR CONTRIBUTIONS}

All authors listed, have made substantial, direct and intellectual contribution to the work, and approved it for publication.

\section{ACKNOWLEDGMENTS}

We apologize to authors whose papers could not be cited owing to space limitations. This work was supported by University "Roma Tre." We are grateful to Dr. Daniele Salvi (CIBIOInBio, Portugal) for useful discussions regarding phylogenetic analysis. Moreover, we deeply thank Dr. Ilaria Fraudentali, Dr. Andrea Carucci, and Dr. Stefano Franchi (Department of Science, University "Roma Tre," Italy) for technical assistance in figure and table preparation.

\section{SUPPLEMENTARY MATERIAL}

The Supplementary Material for this article can be found online at: http://journal.frontiersin.org/article/10.3389/fpls.2016. 00824

Angelini, R., Cona, A., Federico, R., Fincato, P., Tavladoraki, P., and Tisi, A. (2010). Plant amine oxidases "on the move": an update. Plant Physiol. Biochem. 48, 560-564. doi: 10.1016/j.plaphy.2010.02.001

Angelini, R., Tisi, A., Rea, G., Chen, M. M., Botta, M., Federico, R., et al. (2008). Involvement of polyamine oxidase in wound healing. Plant Physiol. 146, 162-177. doi: 10.1104/pp.107.108902

Bollhöner, B., Prestele, J., and Tuominen, H. (2012). Xylem cell death: emerging understanding of regulation and function. J. Exp. Bot. 63, 1081-1094. doi: 10.1093/jxb/err438

Boudart, G., Jamet, E., Rossignol, M., Lafitte, C., Borderies, G., Jauneau, A., et al. (2005). Cell wall proteins in apoplastic fluids of Arabidopsis thaliana rosettes: identification by mass spectrometry and bioinformatics. Proteomics 5, 212-221. doi: $10.1002 /$ pmic. 200400882

Campestre, M. P., Bordenave, C. D., Origone, A. C., Menéndez, A. B., Ruiz, O. A., Rodríguez, A. A., et al. (2011). Polyamine catabolism is involved in response to salt stress in soybean hypocotyls. J. Plant Physiol. 168, 1234-1240. doi: 10.1016/j.jplph.2011.01.007

Cervelli, M., Cona, A., Angelini, R., Polticelli, F., Federico, R., and Mariottini, P. (2001). A barley polyamine oxidase isoform with distinct structural features and subcellular localization. Eur. J. Biochem. 268, 3816-3830. doi: 10.1046/j.14321327.2001.02296.x 
Cheng, W. H., Wang, F. L., Cheng, X. Q., Zhu, Q. H., Sun, Y. Q., Zhu, H. G., et al. (2015). Polyamine and its metabolite $\mathrm{H}_{2} \mathrm{O}_{2}$ play a key role in the conversion of embryogenic callus into somatic embryos in upland cotton (Gossypium hirsutum L). Front. Plant Sci. 6:1063. doi: 10.3389/fpls.2015. 01063

Clay, N. K., and Nelson, T. (2005). Arabidopsis thickvein mutation affects vein thickness and organ vascularization, and resides in a provascular cell-specific spermine synthase involved in vein definition and in polar auxin transport. Plant Physiol. 138, 767-777. doi: 10.1104/pp.104.055756

Cona, A., Cenci, F., Cervelli, M., Federico, R., Mariottini, P., Moreno, S., et al. (2003). Polyamine oxidase, a hydrogen peroxide-producing enzyme, is upregulated by light and down-regulated by auxin in the outer tissues of the maize mesocotyl. Plant Physiol. 131, 803-813. doi: 10.1104/pp.011379

Cona, A., Rea, G., Angelini, R., Federico, R., and Tavladoraki, P. (2006a). Functions of amine oxidases in plant development and defence. Trends Plant Sci. 11, 80-88. doi: 10.1016/j.tplants.2005.12.009

Cona, A., Rea, G., Botta, M., Corelli, F., Federico, R., and Angelini, R. (2006b). Flavin-containing polyamine oxidase is a hydrogen peroxide source in the oxidative response to the protein phosphatase inhibitor cantharidin in Zea mays L. J. Exp. Bot. 57, 2277-2289. doi: 10.1093/jxb/erj195

Cona, A., Tisi, A., Ghuge, S. A., Franchi, S., De Lorenzo, G., and Angelini, R. (2014). Wound healing response and xylem differentiation in tobacco plants over-expressing a fungal endopolygalacturonase is mediated by copper amine oxidase activity. Plant Physiol. Biochem. 82, 54-65. doi: 10.1016/j.plaphy.2014.05.004

Delis, C., Dimou, M., Flemetakis, E., Aivalakis, G., and Katinakis, P. (2006). A root- and hypocotyl-specific gene coding for copper-containing amine oxidase is related to cell expansion in soybean seedlings. J. Exp. Bot. 57, 101-111. doi: $10.1093 / \mathrm{jxb} / \mathrm{erj} 009$

De Pinto, M. C., Locato, V., and De Gara, L. (2012). Redox regulation in plant programmed cell death. Plant Cell Environ. 35, 234-244. doi: 10.1111/j.13653040.2011.02387.x

Dewey, R. E., and Xie, J. (2013). Molecular genetics of alkaloid biosynthesis in Nicotiana tabacum. Phytochemistry 94, 10-27. doi: 10.1016/j.phytochem.2013.06.002

Federico, R., and Angelini, R. (1991). "Polyamine catabolism in plants," in Biochemistry and Physiology of Polyamines in Plants, eds R. D. Slocum and H. E. Flores (Boca Raton, FL: CRC Press), 41-56.

Fincato, P., Moschou, P. N., Ahou, A., Angelini, R., Roubelakis-Angelakis, K. A., and Federico, R. (2012). The members of Arabidopsis thaliana PAO gene family exhibit distinct tissue- and organ-specific expression pattern during seedling growth and flower development. Amino Acids 42, 831-841. doi: 10.1007/s00726-011-0999-7

Fincato, P., Moschou, P. N., Spedaletti, V., Tavazza, R., Angelini, R., and Federico, R. (2011). Functional diversity inside the Arabidopsis polyamine oxidase gene family. J. Exp. Bot. 62, 1155-1168. doi: 10.1093/jxb/erq341

Fuell, C., Elliot, K. A., Hanfrey, C. C., Franceschetti, M., and Michael, A. J. (2010). Polyamine biosynthetic diversity in plants and algae. Plant Physiol. Biochem. 48, 513-520. doi: 10.1016/j.plaphy.2010.02.008

Ge, C., Cui, X., Wang, Y., Hu, Y., Fu, Z., Zhang, D., et al. (2006). BUD2, encoding an $\mathrm{S}$-adenosylmethionine decarboxylase, is required for Arabidopsis growth and development. Cell Res. 16, 446-456. doi: 10.1038/sj.cr.7310056

Ghuge, S. A., Carucci, A., Rodrigues-Pousada, R. A., Tisi, A., Franchi, S., Tavladoraki, P., et al. (2015a). The apoplastic copper AMINE OXIDASE1 mediates jasmonic acid-induced protoxylem differentiation in Arabidopsis roots. Plant Physiol. 168, 690-707. doi: 10.1104/pp.15.00121

Ghuge, S. A., Carucci, A., Rodrigues-Pousada, R. A., Tisi, A., Franchi, S., Tavladoraki, P., et al. (2015b). The MeJA-inducible copper amine oxidase AtAO1 is expressed in xylem tissue and guard cells. Plant Signal Behav. 10:e1073872. doi: $10.1080 / 15592324.2015 .1073872$

Ghuge, S. A., Tisi, A., Carucci, A., Rodrigues-Pousada, R. A., Franchi, S., Tavladoraki, P., et al. (2015c). Cell wall amine oxidases: new players in root xylem differentiation under stress conditions. Plants. 4, 489-504. doi: 10.3390/plants4030489

Gilroy, S., Suzuki, N., Miller, G., Choi, W. G., Toyota, M., Devireddy, A. R., et al. (2014). A tidal wave of signals: calcium and ROS at the forefront of rapid systemic signaling. Trends Plant Sci. 19, 623-630. doi: 10.1016/j.tplants.2014.06.013
Heim, W. G., Sykes, K. A., Hildreth, S. B., Sun, J., Lu, R.-H., and Jelesko, J. G. (2007). Cloning and characterization of a Nicotiana tabacum methylputrescine oxidase transcript. Phytochemistry 68, 454-463. doi: 10.1016/j.phytochem.2006.11.003

Hou, Z.-H., Liu, G.-H., Wang, L.-X., and Liu, X. (2013). Regulatory function of polyamine oxidase-generated hydrogen peroxide in ethylene-induced stomatal closure in Arabidopsis thaliana. J. Integr. Agricult. 12, 251-262. doi: 10.1016/S2095-3119(13)60224-5

Jammes, F., Leonhardt, N., Tran, D., Bousserouel, H., Véry, A. A., Renou, J. P., et al. (2014). Acetylated 1,3-diaminopropane antagonizes abscisic acid-mediated stomatal closing in Arabidopsis. Plant J. 79, 322-333. doi: 10.1111/tpj.12564

Jiménez-Bremont, J. F., Marina, M., Guerrero-González, M., de, L., Rossi, F. R., Sánchez-Rangel, D., Rodríguez-Kessler, M., et al. (2014). Physiological and molecular implications of plant polyamine metabolism during biotic interactions. Front Plant Sci. 5:95. doi: 10.3389/fpls.2014.00095

Kamada-Nobusada, T., Hayashi, M., Fukazawa, M., Sakakibara, H., and Nishimura, M. (2008). A putative peroxisomal polyamine oxidase, AtPAO4, is involved in polyamine catabolism in Arabidopsis thaliana. Plant Cell Physiol. 49, 1272-1282. doi: 10.1093/pcp/pcn114

Kärkönen, A., and Kuchitsu, K. (2015). Reactive oxygen species in cell wall metabolism and development in plants. Phytochemistry. 112, 22-32. doi: 10.1016/j.phytochem.2014.09.016

Katoh, A., Shoji, T., and Hashimoto, T. (2007). Molecular cloning of Nmethylputrescine oxidase from tobacco. Plant Cell Physiol. 48, 550-554. doi: $10.1093 / \mathrm{pcp} / \mathrm{pcm} 018$

Kim, D. W., Watanabe, K., Murayama, C., Izawa, S., Niitsu, M., Michael, A. J., et al. (2014). Polyamine oxidase 5 regulates Arabidopsis growth through thermospermine oxidase activity. Plant Physiol. 165, 1575-1590. doi: $10.1104 /$ pp. 114.242610

Kollist, H., Nuhkat, M., and Roelfsema, M. R. (2014). Closing gaps: linking elements that control stomatal movement. New Phytol. 203, 44-62. doi: $10.1111 /$ nph. 12832

Kuehn, G. D., Rodriguez-Garay, B., Bagga, S., and Phillips, G. C. (1990). Novel occurrence of uncommon polyamines in higher plants. Plant Physiol. 94, 855-857. doi: 10.1104/pp.94.3.855

Lim, T. S., Chitra, T. R., Han, P., Pua, E. C., and Yu, H. (2006). Cloning and characterization of Arabidopsis and Brassica juncea flavin containing amine oxidases. J. Exp. Bot. 57, 4155-4169. doi: 10.1093/jxb/erl193

Liu, T., Kim, D. W., Niitsu, M., Berberich, T., and Kusano, T. (2014a). Oryza sativa polyamine oxidase 1 back-converts tetraamines, spermine and thermospermine, to spermidine. Plant Cell Rep. 33, 143-151. doi: 10.1007/s00299-013-1518-y

Liu, T., Kim, D. W., Niitsu, M., Berberich, T., and Kusano, T. (2014c). POLYAMINE OXIDASE 1 from rice (Oryza sativa) is a functional ortholog of Arabidopsis POLYAMINE OXIDASE 5. Plant Signal Behav. 9:e29773. doi: $10.4161 /$ psb. 29773

Liu, T., Kim, D. W., Niitsu, M., Maeda, S., Watanabe, S., Kamio, Y., et al. (2014b). Polyamine oxidase 7 is a terminal catabolism-type enzyme in Oryza sativa and is specifically expressed in anthers. Plant Cell Physiol. 55, 1110-1122. doi: $10.1093 /$ pcp/pcu047

Marina, M., Sirera, F. V., Rambla, J. L., Gonzalez, M. E., Blázquez, M. A., Carbonell, J., et al. (2013). Thermospermine catabolism increases Arabidopsis thaliana resistance to Pseudomonas viridiflava. J. Exp. Bot. 64, 1393-13402. doi: $10.1093 / \mathrm{jxb} / \mathrm{ert} 012$

McWilliam, H., Li, W., Uludag, M., Squizzato, S., Park, Y. M., Buso, N., et al. (2013). Analysis Tool Web Services from the EMBL-EBI. Nucleic Acids Res. 41, W597-W600. doi: 10.1093/nar/gkt376

Medda, R., Bellelli, A., Peč, P., Federico, R., Cona, A., and Floris, G. (2009). "Copper Amine oxidases from plants," in Copper Amine Oxidases: Structure, Catalytic Mechanism and Role in Pathophysiology, eds G. Floris and B. Mondovi (Boca Raton, FL: Taylor and Francis Group, C.R.C. Press), 39-50.

Medda, R., Padiglia, A., Finazzi Agrò, A., Pedersen, J. Z., Lorrai, A., and Floris, G. (1997). Tryptamine as substrate and inhibitor of lentil seedling copper amine oxidase. Eur. J. Biochem. 250, 377-382.

Mo, H., Wang, X., Zhang, Y., Zhang, G., Zhang, J. F., and Ma, Z. Y. (2015). Cotton polyamine oxidase is required for spermine and camalexin signalling in the defence response to Verticillium dahliae. Plant J. 83, 962-975. doi: $10.1111 /$ tpj.12941 
Møller, S. G., and McPherson, M. J. (1998). Developmental expression and biochemical analysis of the Arabidopsis ataol gene encoding an $\mathrm{H}_{2} \mathrm{O}_{2}$ generating diamine oxidase. Plant J. 13, 781-791. doi: 10.1046/j.1365313X.1998.00080.x

Monshausen, G. B., Bibikova, T. N., Messerli, M. A., Shi, C., and Gilroy, S. (2007). Oscillations in extracellular $\mathrm{pH}$ and reactive oxygen species modulate tip growth of Arabidopsis root hairs. Proc. Natl. Acad. Sci. U.S.A. 104, 20996-21001. doi: 10.1073/pnas.0708586104

Moschou, P. N., Paschalidis, K. A., Delis, I. D., Andriopoulou, A. H., Lagiotis, G. D., Yakoumakis, D. I., et al. (2008a). Spermidine exodus and oxidation in the apoplast induced by abiotic stress is responsible for $\mathrm{H}_{2} \mathrm{O}_{2}$ signatures that direct tolerance responses in tobacco. Plant Cell 20, 1708-1724. doi: $10.1105 /$ tpc. 108.059733

Moschou, P. N., Sanmartin, M., Andriopoulou, A. H., Rojo, E., Sanchez-Serrano, J. J., and Roubelakis-Angelakis, K. A. (2008b). Bridging the gap between plant and mammalian polyamine catabolism: a novel peroxisomal polyamine oxidase responsible for a full back-conversion pathway in Arabidopsis. Plant Physiol. 47, 1845-1857. doi: 10.1104/pp.108.123802

Moschou, P. N., Wu, J., Cona, A., Tavladoraki, P., Angelini, R., and RoubelakisAngelakis, K. A. (2012). The polyamines and their catabolic products are significant players in the turnover of nitrogenous molecules in plants. J. Exp. Bot. 63, 5003-5015. doi: 10.1093/jxb/ers202

Müller, K., Linkies, A., Vreeburg, R. A., Fry, S. C., Krieger-Liszkay, A., and Leubner-Metzger, G. (2009). In vivo cell wall loosening by hydroxyl radicals during cress seed germination and elongation growth. Plant Physiol. 150, 1855-1865. doi: 10.1104/pp.109.139204

Murata, Y., Mori, I. C., and Munemasa, S. (2015). Diverse stomatal signaling and the signal integration mechanism. Annu. Rev. Plant Biol. 66, 369-392. doi: 10.1146/annurev-arplant-043014-114707

Naconsie, M., Kato, K., Shoji, T., and Hashimoto, T. (2014). Molecular evolution of N-methylputrescine oxidase in tobacco. Plant Cell Physiol. 55, 436-444. doi: $10.1093 /$ pcp/pct179

Ono, Y., Kim, D. W., Watanabe, K., Sasaki, A., Niitsu, M., Berberich, T., et al. (2012). Constitutively and highly expressed Oryza sativa polyamine oxidases localize in peroxisomes and catalyze polyamine back conversion. Amino Acids 42, 867-876. doi: 10.1007/s00726-011-1002-3

Padiglia, A., Medda, R., Scanu, T., Longu, S., Rossi, A., and Floris, G. (2002). Structure and nucleotide sequence of Euphorbia characias copper/TPQcontaining amine oxidase gene. J. Protein Chem. 21, 435-441. doi: 10.1023/A:1021337302116

Pál, M., Szalai, G., and Janda, T. (2015). Speculation: polyamines are important in abiotic stress signaling. Plant Sci. 237, 16-23. doi: 10.1016/j.plantsci.2015.05.003

Paschalidis, K. A., and Roubelakis-Angelakis, K. A. (2005). Sites and regulation of polyamine catabolism in the tobacco plant. Correlations with cell division/expansion, cell cycle progression, and vascular development. Plant Physiol. 138, 2174-2184. doi: 10.1104/pp.105.063941

Paschalidis, K. A., Toumi, I., Moschou, N. P., and Roubelakis-Angelakis, K. A. (2010). ABA-dependent amine oxidases-derived $\mathrm{H}_{2} \mathrm{O}_{2}$ affects stomata conductance. Plant Signal Behav. 5, 1153-1156. doi: 10.4161/psb.5.9.12679

Pegg, A. E. (2014). The function of spermine. IUBMB Life 66, 8-18. doi: 10.1002/iub.1237

Pintus, F., Spanò, D., Floris, G., and Medda, R. (2013). Euphorbia characias latex amine oxidase and peroxidase: interacting enzymes? Protein J. 32, 435-441. doi: 10.1007/s10930-013-9501-6

Planas-Portell, J., Gallart, M., Tiburcio, A. F., and Altabella, T. (2013). Copper containing amine oxidases contribute to terminal polyamine oxidation in peroxisomes and apoplast of Arabidopsis thaliana. BMC Plant Biol. 13:109. doi: 10.1186/1471-2229-13-109

Pottosin, I., Velarde-Buendía, A. M., Bose, J., Zepeda-Jazo, I., Shabala, S., and Dobrovinskaya, O. (2014). Cross-talk between reactive oxygen species and polyamines in regulation of ion transport across the plasma membrane: implications for plant adaptive responses. J. Exp. Bot. 65, 1271-1283. doi: $10.1093 / \mathrm{jxb} / \mathrm{ert} 423$

Qu, Y., An, Z., Zhuang, B., Jing, W., Zhang, Q., and Zhang, W. (2014). Copper amine oxidase and phospholipase $\mathrm{D}$ act independently in abscisic acid (ABA)induced stomatal closure in Vicia faba and Arabidopsis. J. Plant Res. 127, 533-544. doi: 10.1007/s10265-014-0633-3
Rea, G., de Pinto, M. C., Tavazza, R., Biondi, S., Gobbi, V., Ferrante, P., et al. (2004). Ectopic expression of maize polyamine oxidase and pea copper amine oxidase in the cell wall of tobacco plants. Plant Physiol. 134, 1414-1426. doi: 10.1104/pp.103.036764

Rea, G., Metoui, O., Infantino, A., Federico, R., and Angelini, R. (2002). Copper amine oxidase expression in defense responses to wounding and Ascochyta rabiei invasion. Plant Physiol. 128, 865-875. doi: 10.1104/pp.010646

Roach, T., Colville, L., Beckett, R. P., Minibayeva, F. V., Havaux, M., and Kranner, I. (2015). A proposed interplay between peroxidase, amine oxidase and lipoxygenase in the wounding-induced oxidative burst in Pisum sativum seedlings. Phytochemistry 112, 130-1388. doi: 10.1016/j.phytochem.2014.06.003

Rodríguez, A. A., Maiale, S. J., Menéndez, A. B., and Ruiz, O. A. (2009). Polyamine oxidase activity contributes to sustain maize leaf elongation under saline stress. J. Exp. Bot. 60, 4249-4262. doi: 10.1093/jxb/erp256

Rossi, A., Petruzzelli, R., and Agrò, A. F. (1992). cDNA-derived amino-acid sequence of lentil seedlings' amine oxidase. FEBS Lett. 301, 253-257. doi: 10.1016/0014-5793(92)80251-B

Sagor, G. H., Inoue, M., Kim, D. W., Kojima, S., Niitsu, M., Berberich, T., et al. (2015). The polyamine oxidase from lycophyte Selaginella lepidophylla (SelPAO5), unlike that of angiosperms, back-converts thermospermine to norspermidine. FEBS Lett. 589, 3071-3078. doi: 10.1016/j.febslet.2015. 08.045

Sagor, G. H. M., Zhang, S., Kojima, S., Simm, S., Berberich, T., and Kusano, T. (2016). Reducing cytoplasmic polyamine oxidase activity in Arabidopsis increases salt and drought tolerance by reducing reactive oxygen species production and increasing defense gene expression. Front. Plant Sci. 7:214. doi: 10.3389/fpls.2016.00214

Schopfer, P., Liszkay, A., Bechtold, M., Frahry, G., and Wagner, A. (2002). Evidence that hydroxyl radicals mediate auxin-induced extension growth. Planta. 214, 821-828. doi: 10.1007/s00425-001-0699-8

Sequera-Mutiozabal, M. I., Erban, A., Kopka J, Atanasov, K. E., Bastida, J., Fotopoulos, V., et al. (2016). Global metabolic profiling of Arabidopsis polyamine oxidase 4 (AtPAO4) loss-of-function mutants exhibiting delayed dark-induced senescence. Front. Plant Sci. 7:173. doi: 10.3389/fpls.2016.00173

Shoresh, M., Spivak, M., and Bernstein, N. (2011). Involvement of calciummediated effects on ROS metabolism in the regulation of growth improvement under salinity. Free Radic Biol Med. 51, 1221-1234. doi: 10.1016/j.freeradbiomed.2011.03.036

Strohm, A. K., Vaughn, L. M., and Masson, P. H. (2015). Natural variation in the expression of ORGANIC CATION TRANSPORTER 1 affects root length responses to cadaverine in Arabidopsis. J. Exp. Bot. 66, 853-862. doi: $10.1093 /$ jxb/eru444

Takahashi, T., and Kakehi, J. (2010). Polyamines: ubiquitous polycations with unique roles in growth and stress responses. Ann. Bot. 105, 1-6. doi: 10.1093/aob/mcp259

Takahashi, Y., Cong, R., Sagor, G. H., Niitsu, M., Berberich, T., and Kusano, T. (2010). Characterization of five polyamine oxidase isoforms in Arabidopsis thaliana. Plant Cell Rep. 29, 955-965. doi: 10.1007/s00299-010-0881-1

Tamura, K., Peterson, D., Peterson, N., Stecher, G., Nei, M., and Kumar, S. (2011). MEGA5: molecular evolutionary genetics analysis using maximum likelihood, evolutionary distance, and maximum parsimony methods. Mol. Biol. Evol. 28, 2731-2739. doi: 10.1093/molbev/msr121

Tavladoraki, P., Cona, A., Federico, R., Tempera, G., Viceconte, N., Saccoccio, S., et al. (2012). Polyamine catabolism: target for antiproliferative therapies in animals and stress tolerance strategies in plants. Amino Acids 42, 411-426. doi: 10.1007/s00726-011-1012-1

Tavladoraki, P., Rossi, M. N., Saccuti, G., Perez-Amador, M. A., Polticelli, F., Angelini, R., et al. (2006). Heterologous expression and biochemical characterization of a polyamine oxidase from Arabidopsis involved in polyamine back conversion. Plant Physiol. 141, 1519-1532. doi: 10.1104/pp.106.080911

Tavladoraki, P., Schininà. M. E., Cecconi, F., Di Agostino, S., Manera, F., Rea, G., et al. (1998). Maize polyamine oxidase: primary structure from protein and cDNA sequencing. FEBS Lett. 426, 62-66. doi: 10.1016/S0014-5793(98)00311-1

Tiburcio, A. F., Altabella, T., Bitrián, M., and Alcázar, R. (2014). The roles of polyamines during the lifespan of plants: from development to stress. Planta 240, 1-18. doi: 10.1007/s00425-014-2055-9 
Tipping, A. J., and McPherson, M. J. (1995). Cloning and molecular analysis of the pea seedling copper amine oxidase. J. Biol. Chem. 270, 16939-16946.

Tisi, A., Federico, R., Moreno, S., Lucretti, S., Moschou, P. N., RoubelakisAngelakis, K. A., et al. (2011). Perturbation of polyamine catabolism can strongly affect root development and xylem differentiation. Plant Physiol. 157, 200-215. doi: 10.1104/pp.111.173153

Tsaniklidis, G., Kotsiras, A., Tsafouros, A., Roussos, P. A., Aivalakis, G., Katinakis, P., et al. (2016). Spatial and temporal distribution of genes involved in polyamine metabolism during tomato fruit development. Plant Physiol. Biochem. 100, 27-36. doi: 10.1016/j.plaphy.2016.01.001

Tsukagoshi, H., Busch, W., and Benfey, P. N. (2010). Transcriptional regulation of ROS controls transition from proliferation to differentiation in the root. Cell 143, 606-616. doi: 10.1016/j.cell.2010.10.020

Tun, N. N., Santa-Catarina, C., Begum, T., Silveira, V., Handro, W., Floh, E. I., et al. (2006). Polyamines induce rapid biosynthesis of nitric oxide (NO) in Arabidopsis thaliana seedlings. Plant Cell Physiol. 47, 346-354. doi: $10.1093 / \mathrm{pcp} / \mathrm{pci} 252$

Wang, W., and Liu, J. H. (2015). Genome-wide identification and expression analysis of the polyamine oxidase gene family in sweet orange (Citrus sinensis). Gene 555, 421-429. doi: 10.1016/j.gene.2014.11.042

Wimalasekera, R., Schaarschmidt, F., Angelini, R., Cona, A., Tavladoraki, P., and Scherer, G. F. (2015). POLYAMINE OXIDASE2 of Arabidopsis contributes to ABA mediated plant developmental processes. Plant Physiol. Biochem. 96, 231-240. doi: 10.1016/j.plaphy.2015.08.003

Wimalasekera, R., Villar, C., Begum, T., and Scherer, G. F. (2011). COPPER AMINE OXIDASE1 (CuAO1) of Arabidopsis thaliana contributes to abscisic acid- and polyamine-induced nitric oxide biosynthesis and abscisic acid signal transduction. Mol. Plant. 4, 663-678. doi: 10.1093/mp/ ssr023

Wu, J., Shang, Z., Wu, J., Jiang, X., Moschou, P. N., Sun, W., et al. (2010). Spermidine oxidase-derived $\mathrm{H}_{2} \mathrm{O}_{2}$ regulates pollen plasma membrane hyperpolarization-activated $\mathrm{Ca}^{2+}$-permeable channels and pollen tube growth. Plant J. 63, 1042-1053. doi: 10.1111/j.1365-313X.2010.04301.x

Yoda, H., Yamaguchi, Y., and Sano, H. (2003). Induction of hypersensitive cell death by hydrogen peroxide produced through polyamine degradation in tobacco plants. Plant Physiol. 132, 1973-1981. doi: 10.1104/pp.103.024737

Yoshimoto, K., Takamura, H., Kadota, I., Motose, H., and Takahashi, T. (2016). Chemical control of xylem differentiation by thermospermine, xylemin, and auxin. Sci. Rep. 6, 21487. doi: 10.1038/srep21487

Zarei, A., Trobacher, C. P., Cooke, A. R., Meyers, A. J., Hall, J. C., and Shelp, B. J. (2015a). Apple fruit copper amine oxidase isoforms: peroxisomal MdAO1 prefers diamines as substrates, whereas extracellular $\mathrm{MdAO} 2$ exclusively utilizes monoamines. Plant Cell Physiol. 56, 137-147. doi: 10.1093/pcp/pcu155

Zarei, A., Trobacher, C. P., and Shelp, B. J. (2015b). NAD ${ }^{+}$-aminoaldehyde dehydrogenase candidates for 4-aminobutyrate (GABA) and $\beta$-alanine production during terminal oxidation of polyamines in apple fruit. FEBS Lett. 589, 2695-2700. doi:10.1016/j.febslet.2015.08.005

Zarza, X., Atanasov, K. E., Marco, F., Arbona, V., Carrasco, P., Kopka, J., et al. (2016). Polyamine oxidase 5 loss-of-function mutations in Arabidopsis thaliana trigger metabolic and transcriptional reprogramming and promote salt stress tolerance. Plant Cell Environ. doi: 10.1111/pce.12714. [Epub ahead of print].

Conflict of Interest Statement: The authors declare that the research was conducted in the absence of any commercial or financial relationships that could be construed as a potential conflict of interest.

Copyright (C) 2016 Tavladoraki, Cona and Angelini. This is an open-access article distributed under the terms of the Creative Commons Attribution License (CC BY). The use, distribution or reproduction in other forums is permitted, provided the original author(s) or licensor are credited and that the original publication in this journal is cited, in accordance with accepted academic practice. No use, distribution or reproduction is permitted which does not comply with these terms. 